\title{
FINANCIAMENTO PÚBLICO DA SAÚDE NOS MUNICÍPIOS BRASILEIROS: ANÁLISE DA QUALIDADE DOS REGISTROS DECLARADOS AO SIOPS DE 2002 A 2014 PARA A ATENÇÃO BÁSICA ${ }^{1}$
}

Aline de Souza ${ }^{2}$

Mônica Viegas Andrade 3

O Sistema de Informações sobre Orçamentos Públicos em Saúde (Siops) é um instrumento fundamental no entendimento da estrutura dos gastos municipais com saúde. Poucos trabalhos testam a confiabilidade das informações do sistema ao nível das subfunções. Este estudo propõe a análise da consistência dos registros do Siops considerando a desagregação para a subfunção atenção básica. Os registros foram analisados para o período 2002-2014. A confiabilidade das informações do Siops foi aferida através da construção de indicadores que associaram a presença de cobertura da Estratégia de Saúde da Família (ESF) à declaração de recebimento de transferências e de gastos com atenção básica. Os principais resultados mostram que os registros de receitas e despesas para a subfunção atenção básica melhoraram no período 2002-2014. Por sua vez, os registros de despesas específicas da ESF apresentaram alto nível de subdeclaração em grande parte dos municípios.

Palavras-chave: Siops; consistência dos registros; atenção básica.

\section{PUBLIC HEALTH FINANCING IN BRAZILIAN MUNICIPALITIES: ANALYSIS OF THE QUALITY OF THE RECORDS DECLARED TO THE SIOPS FROM 2002 TO 2014 FOR PRIMARY HEALTH CARE}

The Information System on Public Health Budgets (Siops) is a fundamental instrument to understand the structure of municipal health expenditures. Few papers test the reliability of the Siops information at the sub-function level. This study proposes the analysis of the consistency of Siops records considering the disaggregation for the primary health care sub-function. The records were analyzed for the period from 2002 to 2014 . The reliability of Siops information was measured through the construction of indicators that associated the coverage by Family Health Strategy (FHS) with the declaration of receipt of transfers and expenditures for primary health care. The main results show that the records of income and expenses for the primary health care sub-function improved during the period from 2002 to 2014. On the other hand, the specific expenditure records of the FHS presented a high level of underreporting in most of the municipalities.

Keywords: Siops; consistency of records; primary health care.

1. DOI: http://dx.doi.org/10.38116/ppp56art9

2. Mestranda em economia no Centro de Desenvolvimento e Planejamento Regional da Universidade Federal de Minas Gerais (Cedeplar/UFMG).E-mail: <asouza@cedeplar.ufmg.br>.

3. Professora associada do Departamento de Ciências Econômicas da UFMG.E-mail: <mviegas@cedeplar.ufmg.br>. 


\title{
FINANCIAMIENTO PÚBLICO DE LA SALUD EN LOS MUNICIPIOS BRASILEÑOS: ANÁLISIS DE LA CALIDAD DE LOS REGISTROS DECLARADOS AL SIOPS DE 2002 A 2014 PARA LA ATENCIÓN PRIMARIA DE SALUD
}

El Sistema de Información sobre Presupuestos Públicos en Salud (Siops) es un instrumento fundamental en el entendimiento de la estructura de los gastos municipales con salud. Pocos estudios prueban la confiabilidad de la información del sistema en el nivel de las subfunciones. Este estudio propone el análisis de la consistencia de los registros del Siops considerando la desagregación para la subfunción atención primaria de salud. Los registros fueron analizados desde 2002 hasta 2014. La confiabilidad de las informaciones del Siops fue evaluada por la construcción de indicadores que asociaron la presencia de cobertura de la Estrategia de Salud de la Familia (ESF) a la declaración de recepción de transferencias y de gastos con atención primaria de salud. Los principales resultados muestran que los registros de ingresos y gastos para la subfunción atención primaria de Salud mejoraron en el período de 2002 al 2014. Por otro lado, los registros de gastos específicos de la ESF presentaron alto nivel de subdeclaración en gran parte de los municipios.

Palabras clave: Siops; consistencia de los registros; atención primaria de salud.

\section{FINANCEMENT DE LA SANTE PUBLIQUE DANS LES MUNICIPALITES BRESILIENNES: ANALYSE DE LA QUALITE DES DOSSIERS DECLARES AU SIOPS DE 2002 A 2014 POUR LES SOINS PRIMAIRES}

\begin{abstract}
Le Système d'Information sur les Budgets Publics en Santé (Siops) est un instrument fondamental pour comprendre la structure des dépenses de santé municipales. Peu d'articles testent la fiabilité des informations système au niveau des sous-fonctions. Cette étude propose l'analyse de la cohérence des enregistrements Siops compte tenu de la désagrégation pour la sous-fonction attention basique. Les enregistrements ont été analysés pour la période de 2002 à 2014. La fiabilité des informations Siops a été mesurée à travers la construction dsindicateurs associant la présence de la couverture de la Stratégie de la Santé Familiale (ESF) à la déclaration de réception des transferts et dépenses avec attention de base. Les principaux résultats montrent que les comptes de recettes et dépenses de la sous-fonction soins de base se sont améliorés entre 2002 et 2014. En revanche, les dossiers de dépenses spécifiques du ESF ont présenté un niveau élevé de sous-déclaration dans la plupart des municipalités.
\end{abstract}

Mots-clés: Siops; cohérence des enregistrements; soins de santé primaires.

JEL: H51; H75; I10.

\section{INTRODUÇÃO}

A descentralização das ações e dos serviços de saúde instituída pela Constituição Federal de 1988 (CF/1988) é uma das diretrizes organizacionais do Sistema Único de Saúde (SUS) e pressupóe a divisão da responsabilidade pela gestão e pelo financiamento da saúde entre todos os entes federados. Um dos objetivos dessa divisão é assegurar o acesso universal e igualitário à saúde, além de facilitar o controle e a fiscalizaçáo dos serviços e recursos por parte da sociedade.

Com a descentralização, os municípios passaram a ter papel significativo na condução da saúde no nível local e no cofinanciamento, principalmente dos gastos 
com atenção primária. Embora o governo federal tenha sido nos anos 1980-1990 o principal financiador público da saúde, nas últimas décadas sua importância vem diminuindo e hoje mais da metade dos gastos é financiado por estados e municípios. De acordo com dados do Sistema de Informaçóes sobre Orçamentos Públicos em Saúde (Siops) e da Subsecretaria de Planejamento e Orçamento (SPO) do Ministério da Saúde (MS), em 2002, cerca de 52\% do gasto público com saúde foi financiado pela União, enquanto, em 2015, essa participação caiu para $43 \%$, e estados e municípios arcaram com $26 \%$ e $31 \%$ do gasto, respectivamente (Vieira e Benevides, 2016).

Desde a criação do SUS, a definição e a regulação da parte que cabe a cada ente no financiamento demorou a ser articulada, comprometendo a oferta de açóes e serviços de saúde. Uma tentativa de organizar o sistema de financiamento se deu com a Emenda Constitucional (EC) no 29/2000, que estabeleceu percentuais mínimos de aplicação na área da saúde. Para estados e Distrito Federal, o percentual mínimo é de $12 \%$ do produto da arrecadação de impostos e dos recursos de transferências federais, enquanto para municípios é de 15\%. Embora a EC no 29/2000 tenha garantido a participação conjunta no financiamento de todos os entes da Federação, o cumprimento pleno dos percentuais só aconteceu após 2012, quando houve a definição do escopo das açóes e serviços públicos de saúde (ASPS) na Lei Complementar (LC) no 141 (Brasil, 2012a, 2012b; Piola et al., 2013).

Para garantir essa estrutura tripartite do financiamento público da saúde, os recursos da União são repassados a estados e municípios por meio de transferências regulares e automáticas do Fundo Nacional de Saúde (FNS) para o Fundo Estadual de Saúde (FNE) e para o Fundo Municipal de Saúde (FMS). Para financiar a atenção básica nos municípios, o governo federal faz transferências referentes ao Piso da Atenção Básica (PAB). Implementado em 1998, o PAB é composto por um componente fixo, estabelecido pelo critério per capita e por uma parte variável, condicionada a adesão dos municípios a programas específicos. Para os municípios que têm pouca capacidade de arrecadação própria, o financiamento da atenção básica é feito quase em sua totalidade com os recursos provenientes das transferências da União, já que as transferências dos estados constituem uma parcela bem menor dos recursos (Prado e Ritzel, 2014).

Considerada como porta de entrada do sistema público de saúde, a atenção básica vem ganhando cada vez mais espaço no Brasil, e os municípios devem ser capazes de, no mínimo, ofertá-la em seus territórios (Brasil, 2004). Além disso, o Pacto pela Saúde 2006 evidencia o compromisso de consolidação da Estratégia de Saúde da Família (ESF) como modelo de atenção básica e como centro ordenador das redes de atençáo à saúde do SUS. Lançada em 1994 pelo MS, inicialmente como um programa (Programa de Saúde da Família - PSF), a ESF é a principal 
ação realizada na esfera da atenção primária no país até então, atuando na cura, prevenção e promoção da saúde, além de realizar encaminhamentos quando há a necessidade de cuidado mais complexo. A equipe multiprofissional da estratégia está ligada às unidades básicas de saúde (UBS) e nesse nível de cuidado são resolvidos cerca de $80 \%$ dos problemas de saúde da população. Desde a década passada têm sido feitos esforços para a ampliação da ESF, sobretudo em áreas rurais e aglomerados urbanos, e a cobertura populacional no país passou de 31,87\% em dezembro de 2002 para 62,48\% em dezembro de 2014 (Brasil, 2018).

Como os municípios desempenham papel-chave no sistema de saúde, é fundamental entender a estrutura dos gastos realizados no âmbito municipal. No contexto brasileiro caracterizado por heterogeneidade socioeconômica, com municípios com portes populacionais e capacidade de gestão muito diferenciados, a composição dos gastos em saúde pode não seguir um padrão entre os municípios. Analisar com o quê, com quanto e como está sendo gasto é essencial para a avaliação do SUS, possibilitando melhorar a gestão dos recursos e a condução das políticas públicas de saúde (Teixeira e Teixeira, 2003).

A avaliação das informaçóes contábeis fornecidas pelos municípios para apuração das receitas e despesas com saúde é essencial para a melhoria da capacidade de gestão. Um primeiro passo importante foi dado com a disponibilização de um sistema nacional e unificado em todo o Brasil, o Siops, implementado a partir de 2000 e definido em 2012 como ferramenta oficial de fiscalização, sendo, portanto, recente a obrigatoriedade de seu uso.

Poucos trabalhos avaliam a qualidade dos dados do Siops em relação aos gastos com atenção básica, que é a principal modalidade de atenção à saúde ofertada pelos municípios.

O uso do Siops para a análise dos dados a um maior nível de agregação é mais comum. Para avaliar o cumprimento da EC no 29/2000, por exemplo, destacam-se os trabalhos de Piola et al. (2012), Piola, França e Nunes (2016), Campelli e Calvo (2007) e Ribeiro, Piola e Servo (2007), que analisam a trajetória e a distribuição do gasto público das três esferas de governo.

Em relação à aderência dos municípios ao Siops, os estudos apontam que o número de municípios que utilizam o sistema aumentou ao longo dos anos (Henrique, 2014; Bezerra et al. 2010; Teixeira e Teixeira, 2003). Contudo, a regularidade na alimentação dos dados bimestrais ao longo do exercício ainda é um problema, pois muitos municípios transmitem as informaçóes fora dos prazos estabelecidos (Henrique, 2014; Silva et al., 2010). Outra questão apontada por Henrique (2014) no estudo realizado com gestores municipais responsáveis pelo 
Siops em Pernambuco foi que apenas $29 \%$ desses gestores afirmaram conhecer muito bem ou bem o sistema. Um problema recorrente na alimentação dos dados é a ausência de participação das secretarias municipais, pois em grande parte dos municípios o preenchimento é feito por profissionais das secretarias de finanças ou por empresas de contabilidade. Dessa forma, fica evidente o hiato existente entre o responsável legal pelo sistema e quem o alimenta de fato (Henrique, 2014; Silva et al., 2010; Sousa et al., 2007).

Quanto à qualidade das informações da atenção básica, sabe-se que a aferição dos recursos próprios não é obtida de forma direta no sistema, sendo necessárias premissas, pois os gastos com atenção básica podem estar declarados em outras subfunçóes, por exemplo. Os trabalhos que usaram essa desagregação indicam que é possível definir o gasto próprio usando os dados do Siops (Prado e Ritzel, 2014; Servo e Paiva, 2013).

Alguns estudos analisam as diferenças entre o Siops e outras fontes de informaçóes contábeis. Um trabalho relevante compara a apuração das receitas e despesas do Siops com os demonstrativos contábeis auditados pelo Tribunal de Contas do Estado - TCE (Gonçalves et al., 2009) e outros dois estudos comparam o Siops com o Finbra (Medeiros et al., 2014; Lima, Carvalho e Schramm, 2006). O Finbra é um banco de dados, criado em 1989 pela Secretaria do Tesouro Nacional (STN) em parceria com a Caixa Econômica Federal (Caixa), que apresenta dados de receitas e despesas dos estados e municípios. O trabalho de Gonçalves et al. (2009) aponta que as discordâncias existentes entre o Siops e os dados do TCE podem ser devidas à falta de consenso dos municípios em relação à composiçấo das receitas e despesas de saúde. Os estudos de Medeiros et al. (2014) e Lima, Carvalho e Schramm et al. (2006) mostram que o Siops apresenta maior clareza metodológica que o Finbra e fornece dados confiáveis quando comparado à essa base.

Este artigo tem como objetivo analisar a consistência dos registros contábeis municipais da atenção básica declarados ao Siops considerando um alto nível de desagregação, englobando as receitas e despesas específicas da ESF. A análise avalia o comportamento desses dados no período 2002-2014. A qualidade do registro será avaliada considerando a consistência do preenchimento das informaçóes com base na cobertura da ESF, não sendo analisada a consistência em termos dos valores declarados e sim em relação à falta de preenchimento dos dados da atenção básica quando o município é coberto pela ESF e à presença de preenchimento quando o município não é coberto. Este estudo é inédito no que se refere à avaliação da qualidade do registro no Siops em âmbito nacional, pois valida as informaçôes em praticamente todo o período de existência do sistema usando a desagregação por subfunção, incluindo a totalidade dos municípios. 
Além desta introdução, o artigo está dividido em outras três seções. A seção 2 descreve a metodologia usada e a construção da base de dados. A seção 3 apresenta os resultados encontrados. A seção 4 traz as consideraçóes finais.

\section{BASE DE DADOS E METODOLOGIA}

\subsection{Siops}

O Siops é um sistema de acesso público do MS criado em 2000 visando disponibilizar diversos tipos de informaçóes sobre receitas e despesas envolvidas em ASPS. Inicialmente, somente estados e municípios declaravam, mas, a partir de 2013, a Uniấo também passou a transmitir as informaçóes. ${ }^{4}$ Desde 2013, o registro no Siops é obrigatório (Decreto $\mathrm{n}^{\mathbf{0}} \mathbf{7 . 8 2 7}$, de outubro de 2012) e deve ser realizado bimestralmente. Um dos principais objetivos do Siops é o monitoramento da aplicação dos recursos pelos entes federados, em cumprimento à LC no ${ }^{\circ}$ 141/2012.

O sistema permite vários níveis de desagregação. O primeiro nível são as subfunções, divididas em: subfunçôes administrativas, subfunções vinculadas e informaçóes complementares. As subfunçôes administrativas são as açôes que têm por finalidade garantir o apoio logístico necessário. As subfunções vinculadas compreendem as açóes típicas de serviços públicos de saúde. Já as informaçôes complementares são açóes que complementam indiretamente e especificamente a saúde. O segundo nível é a desagregação em sete níveis, os quais seguem o ordenamento de contas definido pela STN. As despesas são desagregadas em: i) classe (despesa); ii) categoria econômica, classificada em despesas correntes e despesas de capital; iii) natureza de despesa, que agrupa despesas com as mesmas características quanto ao objeto de gasto; iv) modalidade de aplicação, que indica se os recursos são aplicados diretamente por órgãos ou entidades no âmbito da mesma esfera de governo ou por outro ente da Federaçáo e suas respectivas entidades; v) elemento de despesa, que identifica os objetos do gasto; vi) desdobramento da despesa, que discrimina os elementos da despesa; vii) código específico do Siops. Assim, por exemplo, o código de despesa com saúde 3.3.1.90.11.01.02 representa uma despesa (classe 3), corrente (categoria econômica 3), com pessoal e encargos sociais (natureza da despesa 1), em aplicação direta (modalidade de aplicação 90), com vencimentos e vantagens fixas de pessoal civil (elemento de despesa 11), especificamente vencimentos e salários (desdobramento da despesa 01), do pessoal ativo do PSF (código específico do Siops 02). As receitas são desagregadas em: i) classe (receita); ii) categoria econômica, classificada em receitas correntes e receitas de capital; iii) origem, que identifica a procedência da receita; iv) espécie/rubrica, que identifica com maior detalhamento o que gerou a receita; v) alínea, que identifica o

4. Os dados estão disponíveis, a partir do ano de 1998, para consulta na internet no endereço: <http://siops.datasus.gov.br>. 
nome da receita propriamente dita; vi) subalínea, que detalha a alínea com maior especificidade; vii) um código específico do Siops (Brasil, 2017d).

Além das informaçôes gerais, o Siops disponibiliza alguns indicadores baseados na despesa liquidada e nas receitas pós-dedução, resumo da execução financeira por bloco de financiamento, demonstrativo da saúde através do Relatório Resumido da Execução Orçamentária (RREO) e tabela específica sobre as despesas com saúde executadas em consórcio público.

A fim de garantir a qualidade das informaçóes, o Siops tem um sistema automático de críticas e avisos sobre prováveis erros de preenchimento, gerados devido às inconsistências, ${ }^{5}$ conforme a seguir descrito.

1) Diferença de informação de valores entre a base de dados da STN e/ou do Conselho Nacional de Política Fazendária do Ministério da Fazenda (Confaz/MF) e o que foi declarado no Siops.

2) Diferença de informação de valores entre a base de dados do FNS e o que foi declarado no Siops.

3) Erro de digitação pelo usuário em planilhas de preenchimento do sistema, inclusive em casos de detecção de conflito de informaçáo em um ou mais campos do sistema que deveriam conter a mesma informação de valores.

4) Falta de preenchimento de campos obrigatórios (Brasil, 2017b, p. 8). O sistema não possui críticas para o preenchimento das subfunçôes e dos códigos contábeis, exceto para medicamentos, portanto, essas informaçóes podem não ser declaradas pelos entes federados no momento da transmissão dos dados.

A LC no 141/2012, o Decreto no 7.827/2012 e a Portaria no 53/2013 preveem sançóes aos entes federados que não declaram as informaçóes no Siops no prazo estipulado ou que não aplicam o percentual mínimo em açôes e serviços públicos de saúde. Duas medidas administrativas são possíveis, conforme a seguir descrito.

1) Medida preliminar de redirecionamento de parcela de recursos oriundos de transferências constitucionais para conta específica do fundo de saúde do ente que não demonstrar a aplicação mínima de recursos em açôes e serviços públicos de saúde.

2) Suspensão das transferências constitucionais e voluntárias em decorrência da não homologação dos dados do sexto bimestre do exercício financeiro no Siops, ou pela não demonstraçáo por meio das modalidades contábeis 
(36, 46, 76 e 96), nesse sistema, da aplicação do valor que deixou de ser alocado em açôes e serviços públicos de saúde, após o ente ter sofrido condicionamento de transferências constitucionais pela não declaração das informações homologadas no Siops (Brasil, 2017c).

\subsection{Fontes de dados}

Foram utilizadas quatro fontes de dados, conforme mostra o quadro 1.

1) O Siops, disponibilizado pelo Datasus, para obter informaçóes sobre as receitas e as despesas com saúde no período 2002-2014, considerando-se os municípios que declararam os dados até 25 de abril de $2017 .{ }^{6}$

2) O Departamento de Atenção Básica (DAB), que dispóe no site do MS informaçóes sobre a proporçáo de cobertura populacional estimada por equipes da ESF. Os dados estão disponíveis mensalmente e foram extraídos usando julho (período de meio do ano) como referência temporal. Embora o governo federal tenha lançado a ESF em 1994, os dados estáo disponíveis apenas a partir de 1998.

3) O Instituto Brasileiro de Geografia e Estatística (IBGE), que disponibiliza informações referentes ao produto interno bruto (PIB). Foi utilizado o PIB municipal a preços correntes (referência 2010 para o PIB de 2002 a 2014).

4) O Programa das Nações Unidas para o Desenvolvimento (PNUD), para obter o Índice de Desenvolvimento Humano Municipal (IDHM), a mortalidade infantil e o Índice de Gini, disponíveis no site do Atlas do Desenvolvimento Humano no Brasil, para o ano de 2000 e 2010.

6. A partir de 2002, o Siops passou a adotara codificação contábil estabelecida pela STN e passaram a existir dois sistemas por ano - 0 anual e o semestral. Além disso, para os anos-base anteriores a 2002, algumas consultas não fornecem série histórica, por exemplo. Portanto, optou-se por não incluir os anos de 1998 a 2001 na análise. 
QUADRO 1

Variáveis utilizadas no trabalho

\begin{tabular}{|c|c|c|}
\hline Fonte de dados & Variáveis & Anos \\
\hline Siops & $\begin{array}{l}\text { Subfunções vinculadas: } \\
\text { 301 - Subfunção Atenção Básica } \\
\text { Receita realizada da administração direta e indireta com saúde: } \\
\text { 1.7.21.33.00.10 - Piso de Atenção Básica Fixo (PAB Fixo) } \\
\text { 1.7.21.33.00.20 - Piso de Atenção Básica Ampliado (Paba)² } \\
\text { 1.7.21.33.00.30 - Piso de Atenção Básica Variável (PAB Variável)1 } \\
\text { 1.7.21.33.00.31 - Programa de Saúde da Família (PSF)' } \\
\text { 4.1.7.21.33.11.00 - Atenção Básica } \\
\text { 4.1.7.21.33.11.10 - Piso da Atenção Básica Fixo (PAB Fixo) } \\
\text { 4.1.7.21.33.11.30 - Piso da Atenção Básica Variável (PAB Variável) } \\
\text { 4.1.7.21.33.11.31 - Saúde da Família } \\
\text { Despesa empenhada da administração direta e indireta com saúde: } \\
\text { 3.1.90.04.02.02 - Contratação por Tempo Determinado Programa Saúde da Família (PSF) } \\
\text { 3.1.90.11.01.02 - Pessoal Ativo do PSF } \\
\text { 3.1.90.16.01.02 - Pessoal Ativo do PSF } \\
\text { 3.1.90.34.01.02 - Outras Despesas de Pessoal Contratos Terceirização (PSF) } \\
\text { 3.3.90.04.02.02 - Contratação por Tempo Determinado Programa Saúde da Família } \\
\text { (PSF) } \\
\text { 3.3.90.36.99.02 - Serviços de Terceiros Pessoa Física Programa Saúde da Família (PSF) } \\
\text { Indicadores: } \\
\text { População por município }\end{array}$ & 2002 a 2014 \\
\hline $\mathrm{DAB} / \mathrm{MS}$ & Proporção da população coberta pela ESF & 2002 a 2014 \\
\hline IBGE & PIB a preços correntes & 2002 a 2014 \\
\hline PNUD & $\begin{array}{l}\text { IDHM } \\
\text { Mortalidade infantil } \\
\text { Índice de Gini }\end{array}$ & 2000 e 2010 \\
\hline
\end{tabular}

Elaboração das autoras.

Notas: ${ }^{1}$ Códigos contábeis utilizados no Siops até 2006, quando foram substituídos pelos códigos: 4.1.7.21.33.11.10 - Piso da Atenção Básica (PAB Fixo); 4.1.7.21.33.11.30 - Piso da Atenção Básica Variável (PAB Variável); e 4.1.7.21.33.11.31 Saúde da Família.

${ }^{2} O$ código contábil referente ao PAB Ampliado só consta no Siops para os anos 2002, 2003 e 2004.

${ }^{3}$ Código contábil incluído no Siops a partir de 2007.

\subsection{Construção da base de dados}

Para avaliar a qualidade do registro no Siops, construímos um banco de dados que associa as informaçóes de receitas e despesas com as informaçóes sobre a cobertura da ESF no período 2002-2014. O objetivo é analisar a consistência das informações do Siops avaliando se em determinado ano o município com cobertura da ESF registrou receitas ou despesas com atenção básica.

Como ocorreram mudanças na divisão geopolítica nesse período, principalmente devido à criação de municípios, utilizamos a divisão de 1998, quando o Brasil tinha 5.507 municípios. Entre 1998 e 2013, 63 novos municípios foram criados. As informaçóes referentes aos 63 municípios novos foram somadas aos 
dados dos municípios de origem. No caso de o município ter sido criado pela divisão de mais de uma unidade administrativa, as informaçóes do novo município foram associadas igualmente a todos os municípios de origem. Foram excluídos da análise o Distrito Federal e Fernando de Noronha. O Distrito Federal não é considerado município e seus dados são declarados no Siops estadual. No caso de Fernando de Noronha, não há declaração de informaçôes ao Siops. Assim, a análise utilizou dados para 5.505 municípios no período de estudo de treze anos.

\subsection{Método de análise}

Com o objetivo de analisar se o município reportou receitas e despesas com a subfunção atenção básica e a ESF, verificando apenas o preenchimento dessas informaçóes sem considerar o montante registrado, propomos a construção de indicadores que vinculam a presença da ESF com a declaração de receitas e despesas para avaliar se a qualidade do registro no Siops melhorou ao longo dos anos. Foi realizada uma análise estatística descritiva desses indicadores com base na localização, no grau de desenvolvimento econômico e no porte dos municípios. Em seguida, foi feita uma caracterização socioeconômica e demográfica dos municípios que cometeram erros na declaração dos dados de despesas, ou seja, os municípios cobertos pela ESF que não declaram gastos com atenção básica e ESF e os municípios que não eram cobertos pela ESF e declaram gastos com ESF. A caracterização tem como base os anos de 2000 e 2010, por serem anos-base dos Censos Demográficos 2000 e 2010 e os mais próximos ao período inicial e final da análise para o qual os dados socioeconômicos e demográficos utilizados estão disponíveis.

\subsection{Indicadores}

A informação de cobertura populacional da ESF foi utilizada para separar os municípios cobertos dos não cobertos. Um município com cobertura deve declarar, necessariamente, algum gasto com atenção básica e ESF.

Foram construídos indicadores para conferir se os municípios cobertos pela ESF informaram: receitas de transferências para o financiamento da atenção básica, gastos com a subfunção atenção básica e gastos com a ESF (quadros 2 e 3).

QUADRO 2

Indicador usado para avaliar a consistência dos registros no Siops para a subfunção atenção básica

\begin{tabular}{|c|l|}
\hline Categoria & \multicolumn{1}{|c|}{ Descrição } \\
\hline 1 & Município coberto pela ESF que declarou transferência/gasto no ano com atenção básica. \\
\hline 2 & Município coberto pela ESF que não declarou transferência/gasto no ano com atenção básica. \\
\hline 3 & Município não coberto pela ESF que não declarou transferência/gasto no ano com atenção básica. \\
\hline 4 & Município não coberto pela ESF que declarou transferência/gasto no ano com atenção básica. \\
\hline
\end{tabular}

Elaboração das autoras. 
QUADRO 3

Indicador usado para avaliar a consistência dos registros no Siops para a ESF

\begin{tabular}{|c|l|}
\hline Categoria & \multicolumn{1}{|c|}{ Descrição } \\
\hline 1 & Município coberto pela ESF que declarou transferência/gasto no ano com ESF. \\
\hline 2 & Município coberto pela ESF que não declarou transferência/gasto no ano com ESF. \\
\hline 3 & Município não coberto pela ESF que não declarou transferência/gasto no ano com ESF. \\
\hline 4 & Município não coberto pela ESF que declarou transferência/gasto no ano com ESF. \\
\hline
\end{tabular}

Elaboração das autoras.

Os municípios podem cometer dois erros, que estáo descritos no quadro 4. O erro I está associado aos problemas de consistência dos registros de receitas da atenção básica ou ESF. O erro II está associado aos problemas de consistência dos registros de despesas com atenção básica ou ESF. Ambos se desmembram em três erros (A, B e C), a seguir descritos.

1) O erro I-A ocorre quando o município é coberto pela ESF e não declara nenhuma transferência para a atenção básica. Nesse caso, o município não desagregou as informaçóes das transferências da modalidade fundo a fundo, pois todos os municípios recebem essas transferências para a atenção básica (o PAB), já que elas são obrigatórias e condicionais. O erro I-B ocorre quando o município é coberto pela ESF e não declara nenhuma transferência para a ESF. Nesse caso, o município não declara as informações das transferências específicas que recebe para a atenção básica, isso pode ocorrer porque o mesmo não tem a informação desagregada a esse nível. Dessa forma, seu controle sobre essas transferências seria menos transparente ou deficitário, visto que recebem as transferências federais ao aderirem a programas ou atingir certo nível de produção ou cobertura, como é o caso do PAB Variável para a ESF. O erro I-C ocorre quando o município não é coberto pela ESF e declara transferências para a ESF. Esse erro mostra um total desconhecimento do município sobre suas receitas. Como foi usado apenas um mês para verificar se o município tinha ou não cobertura, pode acontecer de o município ter apresentado cobertura em outro mês do ano e por isso declarou transferências para ESF. Contudo, a cobertura náo tende a variar muito ao longo do ano, portanto esse não é um grande problema.

2) O erro II-A ocorre quando o município é coberto pela ESF e náo declara nenhum gasto com a subfunção atenção básica. O erro II-B ocorre quando o município é coberto pela ESF e não declara nenhum gasto com a ESF para os códigos contábeis. Esses erros vão acontecer quando o município náo tem a informação da despesa desagregada para a subfunção e os códigos contábeis. Isso mostra que o município tem pouco 
conhecimento ou não apresenta de forma transparente as informaçóes sobre o que gasta com atenção básica, principalmente. O erro II-C ocorre quando o município náo é coberto pela ESF e declara gastos com a ESF. Nesse caso, assim como para as transferências, o erro mostra um total desconhecimento do município sobre seus gastos.

QUADRO 4

Erros cometidos pelos municípios na declaração dos dados no Siops

\begin{tabular}{|l|l|l|}
\hline & \multicolumn{1}{|c|}{ Coberto pela ESF } & \multicolumn{1}{|c|}{ Não coberto pela ESF } \\
\hline Município com declaração de transferência para atenção básica. & Informação consistente & Informação consistente \\
\hline Município sem declaração de transferência para atenção básica. & Erro I-A & Informação consistente \\
\hline Município com declaração de transferência para ESF. & Informação consistente & Erro I-C \\
\hline Município sem declaração de transferência para ESF. & Erro I-B & Informação consistente \\
\hline Município com declaração de gasto com atenção básica. & Informação consistente & Informação consistente \\
\hline Município sem declaração de gasto com atenção básica. & Erro II-A & Informação consistente \\
\hline Município com declaração de gasto com ESF. & Informação consistente & Erro II-C \\
\hline Município sem declaração de gasto com ESF. & Erro II-B & Informação consistente \\
\hline
\end{tabular}

Elaboração das autoras.

Vale ressaltar que o município sem cobertura da ESF que declara transferências ou gastos apenas com a atenção básica não comete erro, pois a subfunção engloba outros modelos de organização da atenção básica não baseados na ESF. Esses erros foram considerados para analisar em que medida as desagregaçôes por subfunçôes e códigos contábeis do Siops estão sendo usadas. Dessa forma, pode-se validar o uso dessas desagregaçóes nas análises de financiamento do gasto público com saúde.

\section{RESULTADOS E DISCUSSÃO}

O primeiro resultado relevante é que praticamente a totalidade dos municípios têm transmitido as informaçóes ao Siops. Entre 2002 e 2014, o percentual foi superior a $97 \%$ em todos os anos.

A disseminação do uso do Siops, sobretudo nos dois últimos anos analisados, provavelmente se deve pela aprovação da Lei Complementar no 141/2012, que regulamenta a $E C$ no 29/2000. Com isso, os municípios que não declaram os dados podem sofrer sançóes, já que o cumprimento dos percentuais mínimos é averiguado através das informaçóes transmitidas ao Siops. 
TABELA 1

Situação da entrega dos dados ao Siops pelos municípios (2002-2014)

\begin{tabular}{lcccc}
\hline & \multicolumn{2}{c}{ Transmitiram } & \multicolumn{3}{c}{ Não transmitiram } \\
\hline Ano & Número de municípios & $\%$ & Número de municípios & $\%$ \\
\hline 2002 & 5.454 & 99,07 & 51 & 0,93 \\
2003 & 5.401 & 98,11 & 104 & 1,89 \\
2004 & 5.357 & 97,31 & 148 & 2,69 \\
2005 & 5.491 & 99,75 & 14 & 0,25 \\
2006 & 5.489 & 99,71 & 16 & 0,29 \\
2007 & 5.480 & 99,55 & 25 & 0,45 \\
2008 & 5.454 & 99,07 & 51 & 0,93 \\
2009 & 5.490 & 99,73 & 15 & 0,27 \\
2010 & 5.485 & 99,64 & 20 & 0,36 \\
2011 & 5.467 & 99,31 & 38 & 0,69 \\
2012 & 5.389 & 97,89 & 116 & 2,11 \\
2013 & 5.504 & 99,98 & 1 & 0,02 \\
2014 & 5.505 & 100,00 & 0 & 0,00 \\
\hline
\end{tabular}

Fonte: Siops. Disponível em: <https://bit.ly/3qy9mUn>. Acesso em: 19 maio 2017.

Elaboração das autoras.

Obs.: Número total de municípios $=5.505$.

A análise dos indicadores mostra que, de uma forma geral, houve melhoria nos registros de atenção básica. Os erros tanto relativos ao registro de receitas como de despesas diminuíram no período. O erro I-A, que ocorre quando o município é coberto pela ESF e não declara recebimento de transferências para a atenção básica, foi próximo de zero em todos os anos. O erro II-A, para o município que é coberto e não apresenta gastos com atenção básica, passou de quase $25 \%$ em 2002 para 3\%, aproximadamente, em 2014 (gráfico 1).

Por seu turno, em relação aos registros de despesas com ESF, os erros aumentaram no período, mostrando que o preenchimento da atenção básica na desagregação para a ESF não é satisfatório. $\mathrm{O}$ erro $\mathrm{I}-\mathrm{B}$, que se refere ao município coberto que não declarou recebimento de transferências para a ESF, passou de 0,42\% em 2002 para 11,8\% em 2014. O erro mais cometido foi o II-B, quando o município tem cobertura da ESF e não declarou gastos com a ESF, o qual aumentou de 29,8\% em 2002 para 48,7\% em 2014. Os municípios ainda mostram incapacidade de ter controle dos gastos, pois não têm uma contabilidade que permita desagregar os dados além da subfunção (gráfico 1).

Para os municípios não cobertos, os erros diminuíram ao longo do tempo. $\mathrm{O}$ erro I-C, quando o município não é coberto e declara transferências para a ESF, foi de 4,7\% e 1,2\% em 2002 e 2014, respectivamente. O erro II-C, quando o município não é coberto e declara gastos com a ESF, passou de 4,7\% em 2002 para 1\% em 2014 (gráfico 1). 
GRÁFICO 1

Evolução dos erros cometidos pelos municípios na declaração de dados ao Siops (2002-2014)

(Em \%)

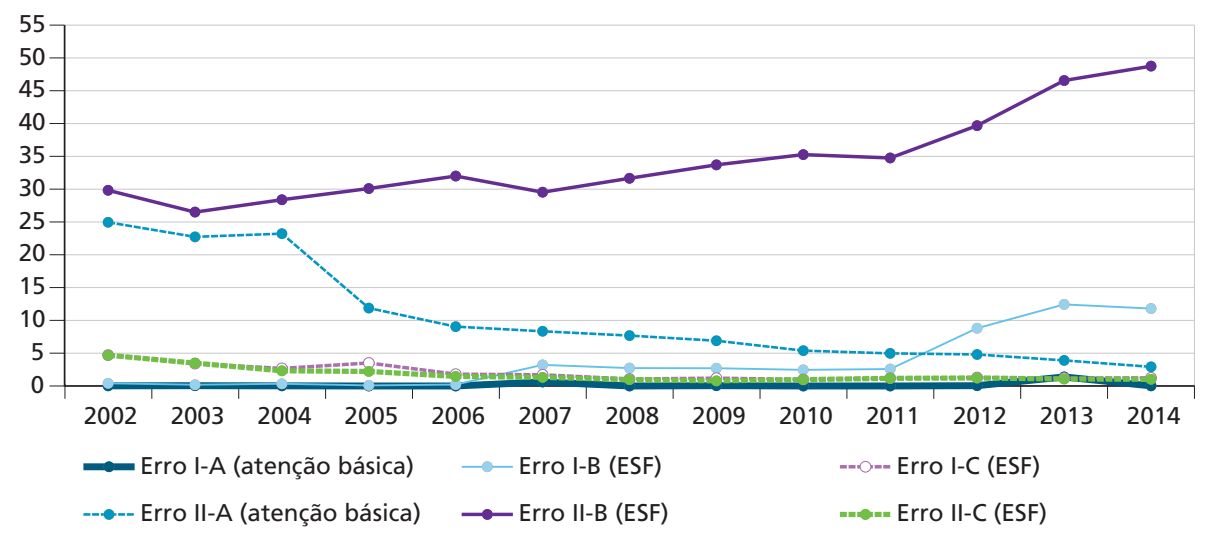

Fontes: Siops (<https://bit.ly/2M2hfma>). Acesso em: 19 maio 2017; e MS (<https://bit.ly/3oY4EyY>). Acesso em: 24 maio 2017. Elaboração das autoras.

A piora mais acentuada dos registros de receita e despesas referentes à ESF observada a partir de 2012 pode estar relacionada com o ciclo político. Gomes (2018) observou redução da qualidade de informaçóes fiscais em anos de eleiçóes, sobretudo municipais, reforçando a existência de influência dos ciclos eleitorais sobre a qualidade dos registros.

\subsection{Evoluç̧ão dos registros de transferências}

Um registro importante para a análise da atenção básica são as receitas advindas de transferências. A tabela 2 apresenta a evoluçáo do registro de transferências, evidenciando a melhora considerável no período analisado. A proporção de municípios cobertos pela ESF que declararam recebimento de transferências para a subfunção passou de 73,74\% em 2002 para 96,7\% em 2014. A análise por regióes mostra que existe uma concentraçáo de piores registros nas regiốes Sudeste e Sul. Embora o porte e o grau de desenvolvimento influenciem na capacidade administrativa dos municípios não foram observadas diferenças na qualidade do registro por esses atributos.

TABELA 2

Evolução do registro de receitas para atenção básica declaradas no Siops ${ }^{1}$

\begin{tabular}{lcccccccc}
\hline & \multicolumn{2}{c}{2002} & \multicolumn{2}{c}{2006} & \multicolumn{2}{c}{2010} & & 2014 \\
\cline { 2 - 9 } & Número & $\%$ & Número & $\%$ & Número & $\%$ & Número & $\%$ \\
\hline $\begin{array}{l}\text { Município coberto e com transfe- } \\
\text { rência no ano }\end{array}$ & 4.022 & 73,74 & 5.042 & 91,86 & 5.202 & 94,84 & 5.323 & 96,69 \\
\hline Região & 412 & 93,00 & 438 & 98,43 & 441 & 99,10 & 440 & 98,88 \\
\hline Centro-Oeste & & & & & & & & \\
\hline
\end{tabular}


(Continuação)

\begin{tabular}{|c|c|c|c|c|c|c|c|c|}
\hline & \multicolumn{2}{|c|}{2002} & \multicolumn{2}{|c|}{2006} & \multicolumn{2}{|c|}{2010} & \multicolumn{2}{|c|}{2014} \\
\hline & Número & $\%$ & Número & $\%$ & Número & $\%$ & Número & $\%$ \\
\hline Nordeste & 1.354 & 77,33 & 1.741 & 98,08 & 1.765 & 99,49 & 1.774 & 99,33 \\
\hline Norte & 306 & 70,34 & 413 & 93,02 & 434 & 98,19 & 439 & 97,77 \\
\hline Sudeste & 1.197 & 71,85 & 1.414 & 84,87 & 1.491 & 89,55 & 1.558 & 93,52 \\
\hline Sul & 753 & 64,97 & 1.036 & 89,39 & 1.071 & 92,41 & 1.112 & 95,94 \\
\hline $\begin{array}{l}\text { (Erro I-A) Município coberto e } \\
\text { sem transferência no ano }\end{array}$ & 1 & 0,02 & - & - & - & - & 1 & 0,02 \\
\hline $\begin{array}{l}\text { Município não coberto e sem } \\
\text { transferência no ano }\end{array}$ & 14 & 0,26 & - & - & - & - & - & - \\
\hline $\begin{array}{l}\text { Município não coberto e com } \\
\text { transferência no ano }\end{array}$ & 1.417 & 25,98 & 447 & 8,14 & 283 & 5,16 & 181 & 3,29 \\
\hline Total & 5.454 & 100,00 & 5.489 & 100,00 & 5.485 & 100,00 & 5.505 & 100,00 \\
\hline
\end{tabular}

Considerando as transferências específicas para a ESF, a proporção de municípios cobertos que declararam recebimento de transferências para a ESF passou de 73,34\% em 2002 para 84,92\% em 2014. Assim como ocorreu com os registros da atenção básica, a análise por regióes mostra que os piores registros foram no Sudeste e Sul. Os piores registros também foram observados entre os municípios com maior grau de desenvolvimento em todos os anos e nos municípios com mais de 50 mil habitantes em 2010 e 2014 (tabela 3).

Os municípios menores têm capacidade limitada de captar recursos próprios para financiar os serviços ofertados, o que torna o registro de receitas mais fácil, uma vez que quase a totalidade de seus recursos é oriunda de transferências da União. Já para os grandes municípios, a maior diversidade das fontes de receita faz com que o registro desagregado seja mais complexo, o que pode explicar os piores resultados para os municípios maiores e de regiôes mais desenvolvidas.

Apesar de os municípios com melhores condições socioeconômicas possuírem um sistema contábil mais estruturado e profissionais mais qualificados, alguns trabalhos que avaliaram o cumprimento da Lei de Responsabilidade Fiscal (LRF) em relação à transparência eletrônica não encontraram correlação entre o grau de desenvolvimento ou o tamanho populacional com melhores registros (Santos et al., 2017; Gama, 2015; Queiroz et al., 2013). Segundo Queiroz et al. (2013), uma explicação para esses resultados divergentes da literatura seria devido à amostra utilizada, já que a maioria dos estudos referentes à transparência fiscal analisaram apenas os grandes municípios, enquanto os trabalhos que não encontraram correlação incluíram também municípios de pequeno porte. 
TABELA 3

Evolução do registro de receitas para ESF declaradas no Siops ${ }^{1}$

\begin{tabular}{|c|c|c|c|c|c|c|c|c|}
\hline & \multicolumn{2}{|c|}{2002} & \multicolumn{2}{|c|}{2006} & \multicolumn{2}{|c|}{2010} & \multicolumn{2}{|c|}{2014} \\
\hline & Número & $\%$ & Número & $\%$ & Número & $\%$ & Número & $\%$ \\
\hline $\begin{array}{l}\text { Município coberto e com transfe- } \\
\text { rência no ano }\end{array}$ & 4.000 & 73,34 & 5.030 & 91,64 & 5.067 & 92,38 & 4.675 & 84,92 \\
\hline \multicolumn{9}{|l|}{ Região } \\
\hline Centro-Oeste & 407 & 91,87 & 438 & 98,43 & 435 & 97,75 & 399 & 89,66 \\
\hline Nordeste & 1.348 & 76,98 & 1.739 & 97,97 & 1.747 & 98,48 & 1.723 & 96,47 \\
\hline Norte & 306 & 70,34 & 413 & 93,02 & 426 & 96,38 & 414 & 92,20 \\
\hline Sudeste & 1.187 & 71,25 & 1.406 & 84,39 & 1.424 & 85,53 & 1.109 & 66,57 \\
\hline Sul & 752 & 64,88 & 1.034 & 89,21 & 1.035 & 89,30 & 1.030 & 88,87 \\
\hline \multicolumn{9}{|l|}{ Porte populacional } \\
\hline Até 10.000 habitantes & 1.953 & 74,63 & 2.370 & 91,29 & 2.285 & 91,88 & 2.010 & 83,68 \\
\hline De 10.001 até 20.000 habitantes & 914 & 68,77 & 1.178 & 91,60 & 1.281 & 94,19 & 1.205 & 87,51 \\
\hline De 20.001 até 50.000 habitantes & 698 & 71,96 & 939 & 91,17 & 983 & 93,53 & 943 & 87,31 \\
\hline $\begin{array}{l}\text { De } 50.001 \text { até } 100.000 \\
\text { habitantes }\end{array}$ & 253 & 81,61 & 294 & 94,23 & 285 & 90,19 & 287 & 82,47 \\
\hline Mais de 100.000 habitantes & 182 & 79,82 & 249 & 93,96 & 233 & 85,98 & 230 & 77,18 \\
\hline \multicolumn{9}{|l|}{ Quintis de PIB per capita } \\
\hline 1ㅇ quintil & 787 & 72,14 & 1.056 & 96,17 & 1.074 & 97,90 & 1.029 & 93,46 \\
\hline $2^{\circ}$ quintil & 853 & 78,19 & 1.053 & 95,90 & 1.064 & 96,99 & 942 & 85,56 \\
\hline $3^{\circ}$ quintil & 824 & 75,53 & 1.013 & 92,26 & 1.002 & 91,34 & 893 & 81,11 \\
\hline $4^{0}$ quintil & 781 & 71,59 & 968 & 88,16 & 973 & 88,70 & 914 & 83,02 \\
\hline 5o- quintil & 755 & 69,27 & 940 & 85,69 & 954 & 86,96 & 897 & 81,47 \\
\hline $\begin{array}{l}\text { (Erro I-B) Município coberto e } \\
\text { sem transferência no ano }\end{array}$ & 23 & 0,42 & 12 & 0,22 & 135 & 2,46 & 649 & 11,79 \\
\hline $\begin{array}{l}\text { Município não coberto e sem } \\
\text { transferência no ano }\end{array}$ & 1.174 & 21,53 & 348 & 6,34 & 228 & 4,16 & 113 & 2,05 \\
\hline $\begin{array}{l}\text { (Erro I-C) Município não coberto } \\
\text { e com transferência no ano }\end{array}$ & 257 & 4,71 & 99 & 1,80 & 55 & 1,00 & 68 & 1,24 \\
\hline Total & 5.454 & 100,00 & 5.489 & 100,00 & 5.485 & 100,00 & 5.505 & 100,00 \\
\hline
\end{tabular}

\subsection{Evolução dos registros de gastos}

O registro de despesas é diferente do registro de receitas. No geral, as receitas são mais agregadas e o volume de transaçóes de despesas é muito maior que o das receitas, portanto, é mais fácil para o município saber o que ele recebeu e registrar esse valor. Já os gastos são mais difíceis de controlar e de registrar. 
A tabela 4 apresenta a evolução do registro de despesas com a subfunção atenção básica. A declaração de gastos com atenção básica apresentou melhora ao longo dos anos. A proporção de municípios cobertos pela ESF que declararam gastos com a atençấo básica em 2002 foi de 48,81\%, aumentando para quase $94 \%$ em 2014. Em relação ao porte e ao desenvolvimento, os piores registros foram para os municípios com até 10 mil habitantes e com maior grau de desenvolvimento.

TABELA 4

Evolução do registro dos gastos com atenção básica declarados no Siops ${ }^{1}$

\begin{tabular}{|c|c|c|c|c|c|c|c|c|}
\hline & \multicolumn{2}{|c|}{2002} & \multicolumn{2}{|c|}{2006} & \multicolumn{2}{|c|}{2010} & \multicolumn{2}{|c|}{2014} \\
\hline & Número & $\%$ & Número & $\%$ & Número & $\%$ & Número & $\%$ \\
\hline $\begin{array}{l}\text { Município coberto e com gasto } \\
\text { no ano }\end{array}$ & 2.662 & 48,81 & 4.546 & 82,82 & 4.907 & 89,46 & 5.163 & 93,79 \\
\hline \multicolumn{9}{|l|}{ Região } \\
\hline Centro-Oeste & 206 & 46,50 & 314 & 70,56 & 345 & 77,53 & 390 & 87,64 \\
\hline Nordeste & 862 & 49,23 & 1.583 & 89,18 & 1.670 & 94,14 & 1.718 & 96,19 \\
\hline Norte & 158 & 36,32 & 383 & 86,26 & 416 & 94,12 & 425 & 94,65 \\
\hline Sudeste & 844 & 50,66 & 1.284 & 77,07 & 1.436 & 86,25 & 1.537 & 92,26 \\
\hline Sul & 592 & 51,08 & 982 & 84,73 & 1.040 & 89,73 & 1.093 & 94,31 \\
\hline \multicolumn{9}{|l|}{ Quintis de PIB per capita } \\
\hline 10 quintil & 469 & 42,99 & 955 & 86,98 & 1.037 & 94,53 & 1.052 & 95,55 \\
\hline $2^{\circ}-$ quintil & 543 & 49,77 & 955 & 86,98 & 1.005 & 91,61 & 1.050 & 95,37 \\
\hline 30 quintil & 533 & 48,85 & 888 & 80,87 & 960 & 87,51 & 1.015 & 92,19 \\
\hline $4^{\circ}$ quintil & 553 & 50,69 & 876 & 79,78 & 945 & 86,14 & 1.016 & 92,28 \\
\hline 50 quintil & 564 & 51,74 & 872 & 79,49 & 960 & 87,51 & 1.030 & 93,55 \\
\hline $\begin{array}{l}\text { (Erro II-A) Município coberto e sem } \\
\text { gasto no ano }\end{array}$ & 1.361 & 24,95 & 496 & 9,04 & 295 & 5,38 & 161 & 2,92 \\
\hline \multicolumn{9}{|l|}{ Região } \\
\hline Centro-Oeste & 206 & 46,50 & 124 & 27,87 & 96 & 21,57 & 50 & 11,24 \\
\hline Nordeste & 492 & 28,10 & 158 & 8,90 & 95 & 5,36 & 56 & 3,14 \\
\hline Norte & 148 & 34,02 & 30 & 6,76 & 18 & 4,07 & 14 & 3,12 \\
\hline Sudeste & 353 & 21,19 & 130 & 7,80 & 55 & 3,30 & 22 & 1,32 \\
\hline Sul & 162 & 13,98 & 54 & 4,66 & 31 & 2,67 & 19 & 1,64 \\
\hline $\begin{array}{l}\text { Município não coberto e sem gasto } \\
\text { no ano }\end{array}$ & 510 & 9,35 & 55 & 1,00 & 23 & 0,42 & 11 & 0,20 \\
\hline $\begin{array}{l}\text { Município não coberto e com gasto } \\
\text { no ano }\end{array}$ & 921 & 16,89 & 392 & 7,14 & 260 & 4,74 & 170 & 3,09 \\
\hline Total & 5.454 & 100,00 & 5.489 & 100,00 & 5.485 & 100,00 & 5.505 & 100,00 \\
\hline
\end{tabular}


A análise para a subfunção atenção básica permite o uso dos dados para aferir os gastos, pois os registros se mostraram consistentes. Os municípios estão lançando as informações, mas a validação da totalidade dos valores que estão sendo lançados é um estudo à parte. Devido à importância da ESF para a atenção primária é fundamental que também se tenha uma validaçáo dos dados mais desagregados para que sejam possíveis avaliaçóes econômicas do programa.

A tabela 5 mostra a evolução do registro de despesas da ESF. Em 2002 44\% dos municípios cobertos pela ESF declararam gastos com a ESF desagregados por códigos contábeis e em 2014 a proporção foi de $48 \%$. Assim como para a atenção básica, os piores registros foram os dos municípios com maior grau de desenvolvimento. A análise por porte indica que os piores registros são dos municípios com população acima de 50 mil habitantes.

Para registros mais desagregados os piores resultados novamente foram observados entre municípios maiores. No geral, municípios pequenos têm mais controle dos gastos, pois em grande parte desses municípios a ESF é a única forma de organização da atenção básica. Por sua vez, os municípios maiores contam com uma rede de atenção à saúde mais abrangente e a atenção básica não está organizada apenas através da ESF, pois esta envolve serviços que exigem um sistema de contrataçốes mais complexo, o que dificulta o registro mais detalhado de gastos.

TABELA 5

Evolução do registro dos gastos com ESF declarados no Siops ${ }^{1}$

\begin{tabular}{|c|c|c|c|c|c|c|c|c|}
\hline & \multicolumn{2}{|c|}{2002} & \multicolumn{2}{|c|}{2006} & \multicolumn{2}{|c|}{2010} & \multicolumn{2}{|c|}{2014} \\
\hline & Número & $\%$ & Número & $\%$ & Número & $\%$ & Número & $\%$ \\
\hline $\begin{array}{l}\text { Município coberto e com } \\
\text { gasto no ano }\end{array}$ & 2.396 & 43,93 & 3.286 & 59,87 & 3.268 & 59,58 & 2.641 & 47,97 \\
\hline \multicolumn{9}{|l|}{ Região } \\
\hline Centro-Oeste & 247 & 55,76 & 251 & 56,40 & 237 & 53,26 & 183 & 41,12 \\
\hline Nordeste & 700 & 39,98 & 1.196 & 67,38 & 1.218 & 68,66 & 861 & 48,21 \\
\hline Norte & 164 & 37,70 & 286 & 64,41 & 288 & 65,16 & 262 & 58,35 \\
\hline Sudeste & 758 & 45,50 & 881 & 52,88 & 878 & 52,73 & 715 & 42,92 \\
\hline Sul & 527 & 45,47 & 672 & 57,98 & 647 & 55,82 & 620 & 53,49 \\
\hline \multicolumn{9}{|l|}{ Porte populacional } \\
\hline Até 10.000 habitantes & 1.176 & 44,94 & 1.570 & 60,48 & 1.529 & 61,48 & 1.223 & 50,92 \\
\hline $\begin{array}{l}\text { De } 10.001 \text { até } 20.000 \\
\text { habitantes }\end{array}$ & 516 & 38,83 & 782 & 60,81 & 832 & 61,18 & 659 & 47,86 \\
\hline $\begin{array}{l}\text { De } 20.001 \text { até } 50.000 \\
\text { habitantes }\end{array}$ & 428 & 44,12 & 612 & 59,42 & 610 & 58,04 & 495 & 45,83 \\
\hline
\end{tabular}


Financiamento Público da Saúde nos Municípios Brasileiros: análise da qualidade dos registros declarados ao Siops de 2002 a 2014 para a atenção básica

(Continuação)

\begin{tabular}{|c|c|c|c|c|c|c|c|c|}
\hline & \multicolumn{2}{|c|}{2002} & \multicolumn{2}{|c|}{2006} & \multicolumn{2}{|c|}{2010} & \multicolumn{2}{|c|}{2014} \\
\hline & Número & $\%$ & Número & $\%$ & Número & $\%$ & Número & $\%$ \\
\hline $\begin{array}{l}\text { De } 50.001 \text { até } 100.000 \\
\text { habitantes }\end{array}$ & 162 & 52,26 & 182 & 58,33 & 177 & 56,01 & 152 & 43,68 \\
\hline Mais de 100.000 habitantes & 114 & 50,00 & 140 & 52,83 & 120 & 44,28 & 112 & 37,58 \\
\hline \multicolumn{9}{|l|}{$\begin{array}{l}\text { Quintis de PIB } \\
\text { per capita }\end{array}$} \\
\hline 10 quintil & 367 & 33,64 & 722 & 65,76 & 759 & 69,19 & 575 & 52,23 \\
\hline $2^{\circ}$ quintil & 503 & 46,10 & 725 & 66,03 & 727 & 66,27 & 551 & 50,05 \\
\hline 30 quintil & 522 & 47,85 & 649 & 59,11 & 619 & 56,43 & 493 & 44,78 \\
\hline $4^{0}$ quintil & 498 & 45,65 & 602 & 54,83 & 581 & 52,96 & 521 & 47,32 \\
\hline 5o quintil & 506 & 46,42 & 588 & 53,60 & 582 & 53,05 & 501 & 45,50 \\
\hline $\begin{array}{l}\text { (Erro II-B) Município coberto } \\
\text { e sem gasto no ano }\end{array}$ & 1.627 & 29,83 & 1.756 & 31,99 & 1.934 & 35,26 & 2.683 & 48,74 \\
\hline \multicolumn{9}{|l|}{ Região } \\
\hline Centro-Oeste & 165 & 37,25 & 187 & 42,02 & 204 & 45,84 & 257 & 57,75 \\
\hline Nordeste & 654 & 37,35 & 545 & 30,70 & 547 & 30,83 & 913 & 51,12 \\
\hline Norte & 142 & 32,64 & 127 & 28,60 & 146 & 33,03 & 177 & 39,42 \\
\hline Sudeste & 439 & 26,35 & 533 & 31,99 & 613 & 36,82 & 844 & 50,66 \\
\hline Sul & 227 & 19,59 & 364 & 31,41 & 424 & 36,58 & 492 & 42,45 \\
\hline \multicolumn{9}{|l|}{ Porte populacional } \\
\hline Até 10.000 habitantes & 789 & 30,15 & 800 & 30,82 & 798 & 32,09 & 1.063 & 44,25 \\
\hline $\begin{array}{l}\text { De } 10.001 \text { até } 20.000 \\
\text { habitantes }\end{array}$ & 401 & 30,17 & 397 & 30,87 & 477 & 35,07 & 691 & 50,18 \\
\hline $\begin{array}{l}\text { De } 20.001 \text { até } 50.000 \\
\text { habitantes }\end{array}$ & 275 & 28,35 & 333 & 32,33 & 399 & 37,96 & 565 & 52,31 \\
\hline $\begin{array}{l}\text { De } 50.001 \text { até } 100.000 \\
\text { habitantes }\end{array}$ & 91 & 29,35 & 113 & 36,22 & 126 & 39,87 & 184 & 52,87 \\
\hline Mais de 100.000 habitantes & 71 & 31,14 & 113 & 42,64 & 134 & 49,45 & 180 & 60,40 \\
\hline $\begin{array}{l}\text { Município não coberto e sem } \\
\text { gasto no ano }\end{array}$ & 1.175 & 21,54 & 367 & 6,69 & 229 & 4,18 & 125 & 2,27 \\
\hline $\begin{array}{l}\text { (Erro II-C) Município não } \\
\text { coberto e com gasto no ano }\end{array}$ & 256 & 4,69 & 80 & 1,46 & 54 & 0,98 & 56 & 1,02 \\
\hline Total & 5.454 & 100,00 & 5.489 & 100,00 & 5.485 & 100,00 & 5.505 & 100,00 \\
\hline
\end{tabular}

Fontes: Siops (<https://bit.ly/2M2hfma>). Acesso em: 19 maio 2017; e MS (<https://bit.ly/3oY4EyY>). Acesso em: 24 maio 2017. Elaboração das autoras.

Nota: ${ }^{1}$ Foram omitidos os municípios que não transmitiram os dados ao Siops. 
A implantação de um Sistema de Controle Interno (SCI) nos municípios é apontada como essencial para assegurar a qualidade das informaçōes das prestaçóes de contas, fornecendo meios para que medidas corretivas proativas sejam tomadas. A instauração de controle interno que tenha mais foco no Siops poderia resolver o problema de muitas informaçôes inconsistentes, sobretudo no preenchimento das despesas. Contudo, alguns estudos que analisaram o efeito da implantação do SCI apontam que este não melhora a qualidade dos registros na prática, demonstrando que é necessário um esforço maior para que o controle interno seja mais consistente (Rodrigues, Bartoluzzio e Miranda, 2018; Vasconcelos et al., 2012; Cavalcante, Peter e Machado, 2011).

\subsection{Distribuição espacial dos municípios que cometeram erros na declaração de gastos ao Siops}

Como os maiores problemas de declaração ocorreram para as despesas, foi realizada a distribuição espacial dos municípios que apresentaram informações inconsistentes no registro de gastos em 2002 e 2014 a fim de facilitar a percepção das mudanças ocorridas no período tanto em relaçáo à quantidade de municípios com declaraçóes inconsistentes quanto em relação à concentração regional (figuras 1 a 6).7

Para os gastos com atenção básica, a análise regional reforça que os dados são confiáveis. O erro II-A, que se refere aos municípios cobertos pela ESF que não declararam gastos com atenção básica, está representado nas figuras 1 e 2 . Observa-se uma diminuição significativa dos municípios que cometeram o erro de 2002 para 2014. Em 2002, os municípios que apresentaram informaçóes inconsistentes estavam distribuídos mais uniformemente entre as regióes do país e em 2014 estavam mais concentrados na regiáo Centro-Oeste.

7. Os municípios que aparecem em branco não entraram na análise por terem sido criados após 1998 ou por não terem transmitidos os dados ao Siops. 
FIGURA 1

Municípios que cometeram o erro II-A (2002)

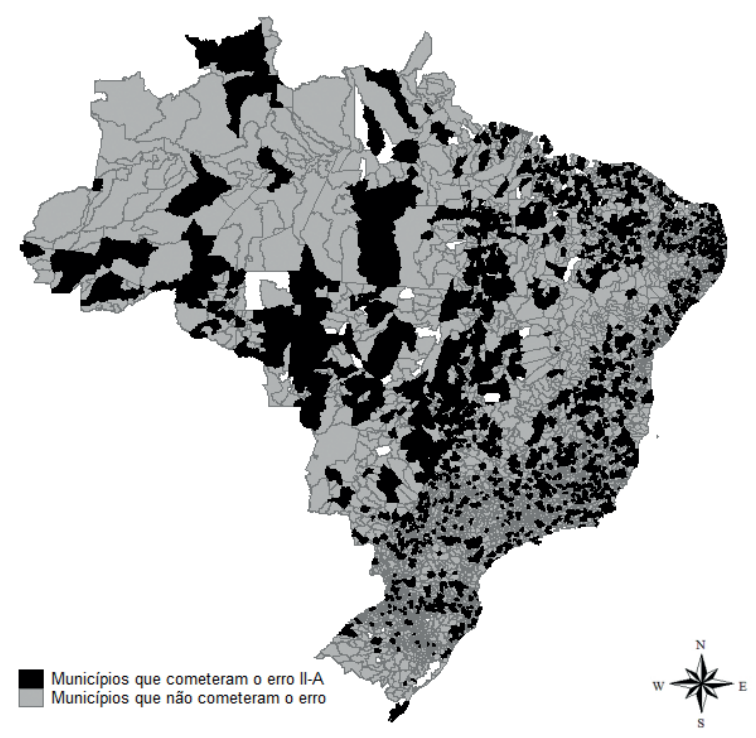

Fontes: IBGE (<https://bit.ly/3qATVuw>). Acesso em 22 set. 2017; e Siops (<https://bit.ly/392QeYV>). Acesso em: 19 maio 2017. Elaboração das autoras.

FIGURA 2

Municípios que cometeram o erro II-A (2014)

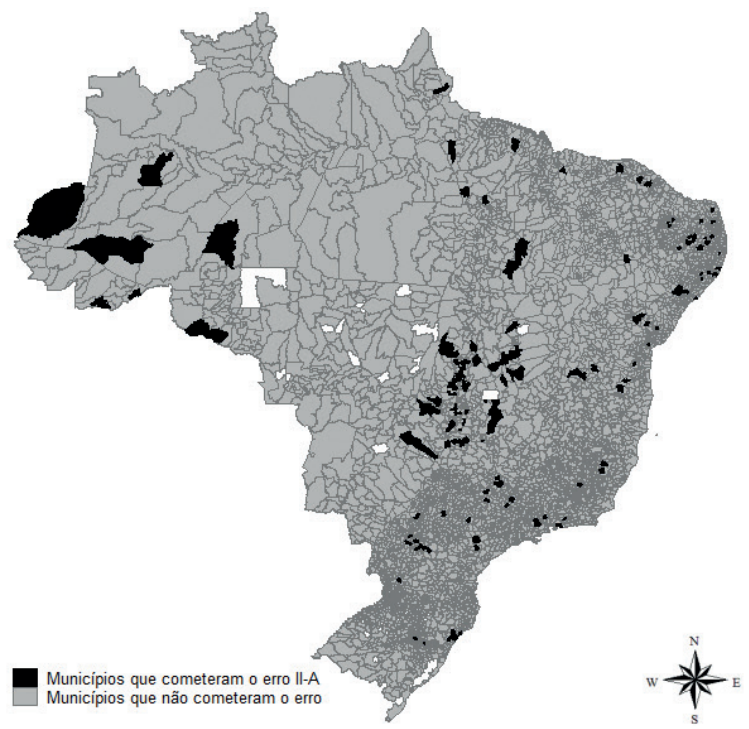

Fontes: IBGE (<https://bit.ly/3qATVuw>). Acesso em 22 set. 2017; e Siops (<https://bit.ly/392QeYV>). Acesso em: 19 maio 2017. Elaboração das autoras. 
Para os gastos com ESF, a análise regional mostra que para todas as regiōes os registros não são confiáveis para os municípios cobertos. O erro II-B, referente aos municípios cobertos pela ESF que não declararam gastos específicos com a ESF, está representado nas figuras 3 e 4 . A quantidade de municípios com declaraçôes inconsistentes aumentou de 2002 para 2014 em todas as regióes, principalmente no Sudeste, no Sul e no Centro-Oeste. Para os municípios não cobertos, os registros são confiáveis.

\section{FIGURA 3}

Municípios que cometeram o erro II-B (2002)

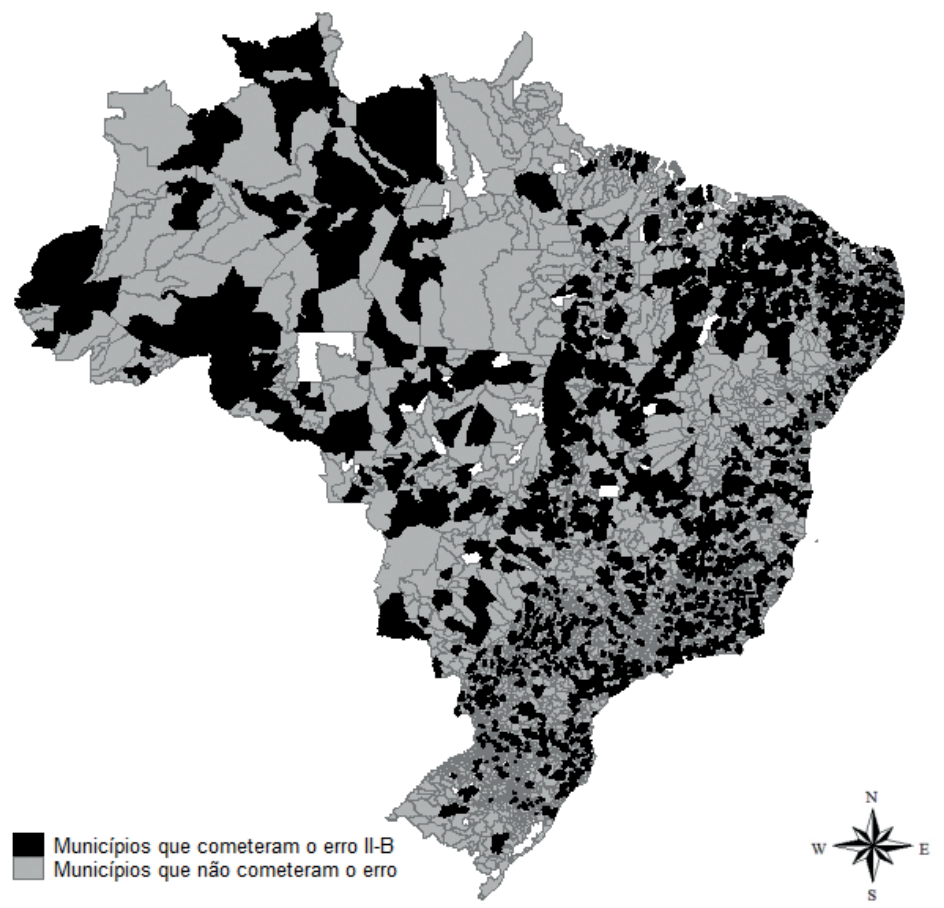

Fontes: IBGE (<https://bit.ly/3qATVuw>). Acesso em 22 set. 2017; e Siops (<https://bit.ly/392QeYV>). Acesso em: 19 maio 2017. Elaboração das autoras. 


\section{FIGURA 4}

Municípios que cometeram o erro II-B (2014)

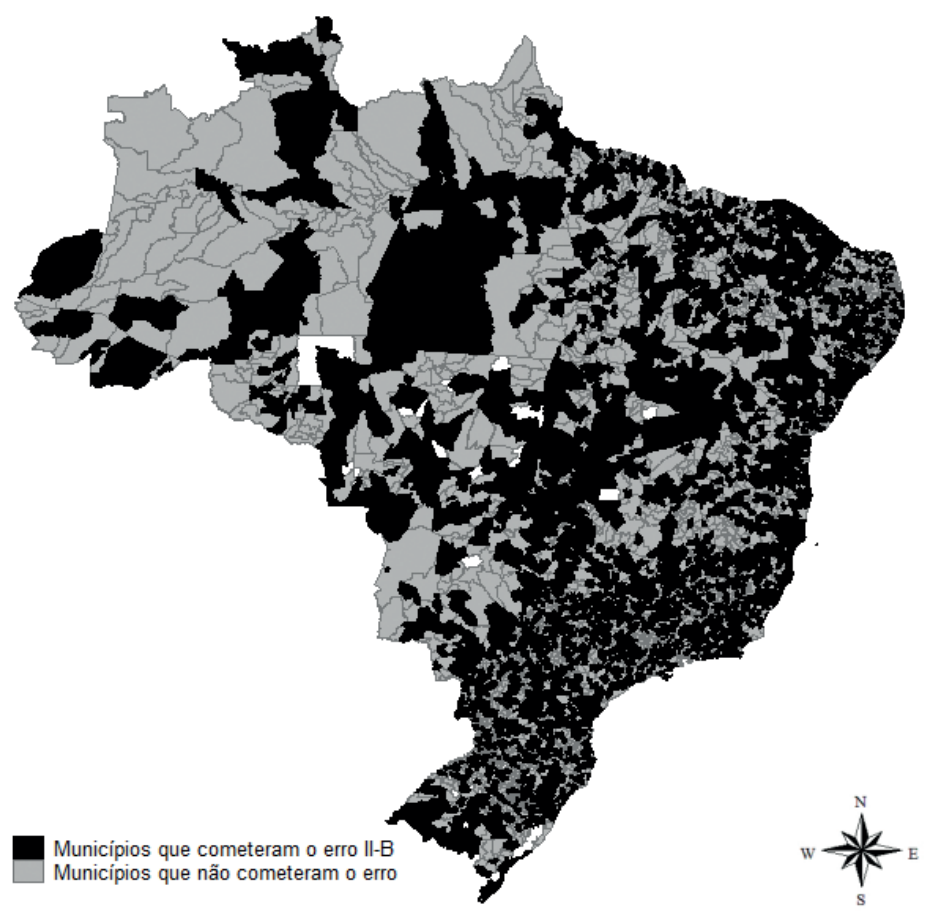

Fontes: IBGE (<https://bit.ly/3qATVuw>). Acesso em 22 set. 2017; e Siops (<https://bit.ly/392QeYV>). Acesso em: 19 maio 2017. Elaboração das autoras.

O erro II-C, referente aos municípios não cobertos pela ESF que declararam gastos específicos com a ESF, pode ser observado nas figuras 5 e 6 . A quantidade de municípios que apresentaram informaçóes inconsistentes nos dois anos analisados foi muito baixa e diminuiu de 2002 para 2014. Em 2002, os municípios com declaraçóes inconsistentes estavam concentrados nas regióes Nordeste, Sudeste e Sul e em 2014 a regiāo com maior concentração desses municípios foi a Sudeste. 
FIGURA 5

Municípios que cometeram o erro II-C (2002)

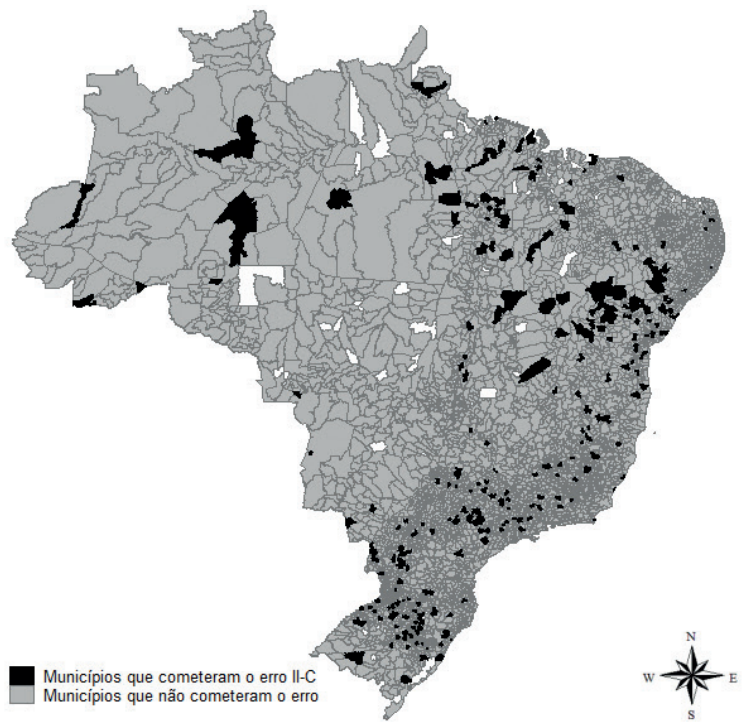

Fontes: IBGE (<https://bit.ly/3qATVuw>). Acesso em 22 set. 2017; e Siops (<https://bit.ly/392QeYV>). Acesso em: 19 maio 2017. Elaboração das autoras.

FIGURA 6

Municípios que cometeram o erro II-C (2014)

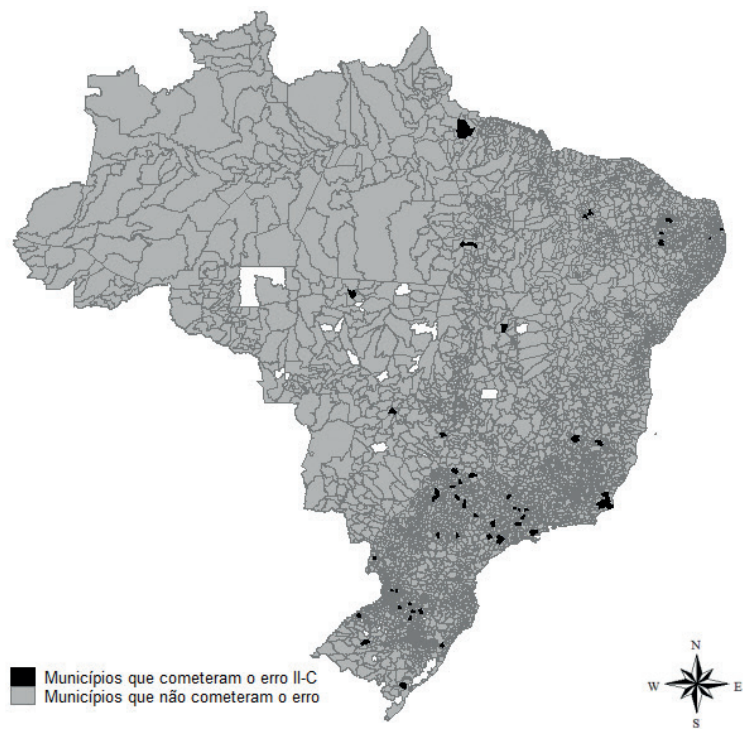

Fontes: IBGE (<https://bit.ly/3qATVuw>). Acesso em 22 set. 2017; e Siops (<https://bit.ly/392QeYV>). Acesso em: 19 maio 2017. Elaboração das autoras. 


\subsection{Características dos municípios que cometeram erros na declaração de gastos ao Siops}

A tabela 6 apresenta as características socioeconômicas e demográficas dos municípios cobertos pela ESF que não declararam gastos com atenção básica e ESF em 2002 e 2014 (erro II-A e erro II-B) e dos não cobertos pela ESF que declararam gastos específicos com a ESF (erro II-C). As características dos municípios que apresentaram informaçóes inconsistentes foram semelhantes às do total de municípios que declararam os dados ao Siops, sobretudo em 2014. Para os municípios que transmitiram os dados em 2002, mortalidade infantil foi um dos indicadores com a maior diferença. Os municípios que cometeram os erros II-A e II-B apresentaram taxa de mortalidade infantil de 35,61 e 36,01, respectivamente, enquanto a taxa do total de municípios que transmitiram os dados foi de 33,23. Embora em 2002 os municípios com declaraçóes inconsistentes tenham apresentado maior desigualdade e piores indicadores, as diferenças em relação ao total de municípios que declararam os dados ao Siops não foram muito grandes e diminuíram ao longo do tempo. 


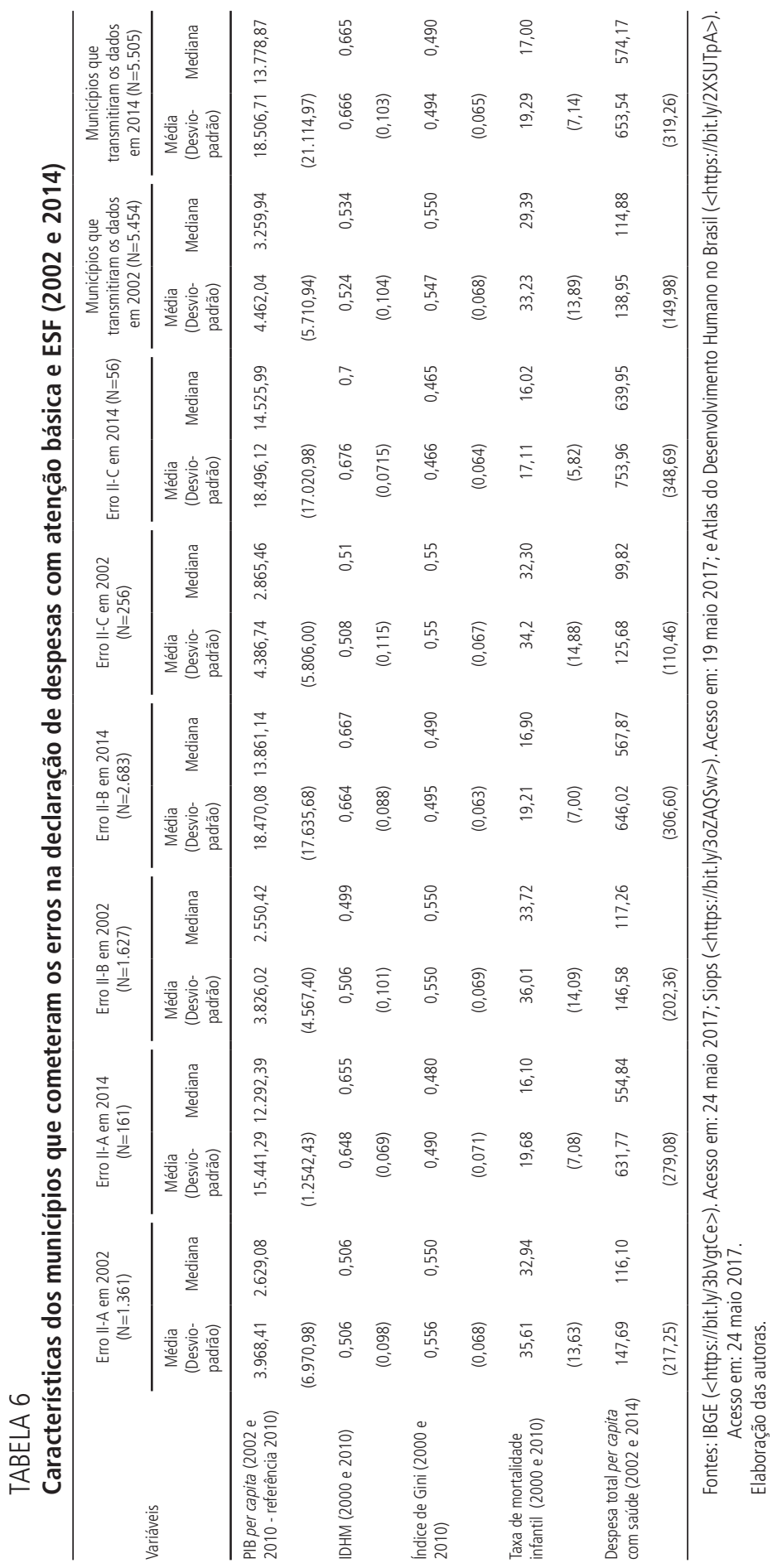




\subsection{Persistência dos municípios em cometer os erros relacionados aos gastos}

Por fim, analisou-se a persistência dos municípios em cometer os erros, ou seja, em quantos anos o mesmo município comete o mesmo erro. Cerca de $56 \%$ dos municípios que eram cobertos pela ESF não declararam gastos com atençáo básica (erro II-A) em um ou dois anos e 58\% dos municípios que eram cobertos pela ESF não declararam gastos específicos com a ESF (erro II-B) entre um e cinco anos. Quase 74\% dos municípios cometeram o erro II-C (municípios não cobertos que declararam gastos com ESF) apenas em um ano durante o período analisado. A proporção de municípios que cometem os mesmos erros em todos os anos foi muito baixa, não passando de 1,3\% (tabela 7). A persistência no erro tende a diminuir com o tempo devido ao aprendizado e maior familiarização com os dados e com a plataforma do Siops.

TABELA 7

Persistência dos municípios nos erros relacionados às despesas (2002-2014) ${ }^{1}$

\begin{tabular}{lcccccc}
\hline \multirow{2}{*}{$\begin{array}{l}\text { Quantidade de anos que } \\
\text { município errou }\end{array}$} & \multicolumn{2}{c}{ Erro II-A } & \multicolumn{2}{c}{ Erro II-B } & \multicolumn{3}{c}{ Erro II-C } \\
\cline { 2 - 7 } & Número & $\%$ & Número & $\%$ & Número & $\%$ \\
\hline 1 & 888 & 36,20 & 651 & 13,67 & 664 & 73,94 \\
2 & 498 & 20,30 & 610 & 12,81 & 162 & 18,04 \\
3 & 394 & 16,06 & 551 & 11,57 & 48 & 5,35 \\
4 & 199 & 8,11 & 493 & 10,35 & 18 & 2,00 \\
5 & 103 & 4,20 & 453 & 9,51 & 3 & 0,33 \\
6 & 98 & 4,00 & 444 & 9,32 & 3 & 0,33 \\
7 & 72 & 2,94 & 396 & 8,32 & - & - \\
8 & 66 & 2,69 & 338 & 7,10 & - & - \\
9 & 45 & 1,83 & 296 & 6,22 & - & - \\
10 & 20 & 0,82 & 219 & 4,60 & - & - \\
11 & 27 & 1,10 & 150 & 3,15 & - & - \\
12 & 25 & 1,02 & 99 & 2,08 & - & - \\
13 & 18 & 0,73 & 62 & 1,30 & - & 100,00 \\
\hline Total & 25 & 100,00 & 4.762 & 100 & 898 & - \\
\hline
\end{tabular}

Fontes: Siops (https://bit.ly/38YhOq8). Acesso em: 19 maio 2017; e MS (https://bit.ly/3ivBXXM). Acesso em: 24 maio 2017. Elaboração das autoras.

Nota: ${ }^{1}$ Foram omitidos os municípios que não transmitiram os dados ao Siops.

\section{CONSIDERAÇÕES FINAIS}

Este artigo é o primeiro que sistematiza a qualidade do registro no Siops para a totalidade de municípios no Brasil usando a subfunção atenção básica, se tratando, portanto, de um estudo inédito. As informaçôes são validadas em quase toda a 
existência do sistema (treze anos), sendo indicadas quais são confiáveis. Além disso, este estudo caracteriza os municípios que apresentam declaraçóes inconsistentes. A partir dessas informaçóes é possível verificar que, no geral, as características socioeconômicas e demográficas dos municípios com declaraçôes inconsistentes não são muito diferentes da média e que os municípios da regiáo Centro-Oeste apresentam mais informações inconsistentes. Com isso, as intervenções podem ser mais facilmente direcionadas aos municípios com maiores problemas.

Também foi observado que o número de municípios que declararam os dados ao Siops aumentou durante os anos, chegando a $100 \%$ em 2014. Os resultados indicam que as informaçóes de receitas demonstram maior facilidade de registro que as de despesas. Chama a atenção ainda a maior dificuldade no registro de despesas mais desagregadas, como as despesas específicas da ESF, em que o preenchimento dos dados apresenta inconsistências. Para uma desagregaçáo que náo requer tanto controle, os dados são confiáveis. As declarações para as subfunçóes são mais simples e exigem menor detalhamento, apresentando melhores resultados na qualidade dos registros. Em termos de consistência, os dados da subfunção atenção básica estão bons, mas a magnitude dos valores pode estar subdeclarada. Alguns municípios declaram os gastos da atenção básica em outras subfunçôes dependendo da forma de contratação de serviços, por exemplo. Prado e Ritzel (2014) e Servo e Paiva (2013) apontam que os dados de despesa com atenção básica contidos no Siops precisam de correçóes e propóem uma metodologia para aferir tais gastos.

As críticas que contém no Siops são um instrumento importante para que o preenchimento seja mais consistente, mas não podem ser usadas em muitos campos, pois poderiam gerar o efeito contrário e piorar a qualidade dos dados, uma vez que os municípios passariam a informar quaisquer dados para não serem punidos devido à falta de transmissão das informaçôes. Deve ser estudada a possibilidade de inserção de novas críticas ou aviso, além de um sistema de incentivo aos municípios vinculados ao Siops para que as declaraçóes sejam mais detalhadas e preservem a confiabilidade. Espera-se também que à medida que os dados forem mais utilizados a necessidade de novas críticas apareçam.

A equipe do Siops e o MS promovem regularmente capacitaçóes para o preenchimento das informaçôes orçamentárias em Brasília, além de realizarem o Curso Siops Itinerante em vários estados e regióes desde 2016. Contudo, esses esforços ainda não são satisfatórios, já que o investimento em cursos de capacitação é insuficiente. A conscientização dos gestores sobre a importância das informações do Siops deve ser promovida constantemente para que os dados sejam vistos como ferramentas indispensáveis para o planejamento e a gestão municipal e não apenas como forma de fiscalização. 
Até o momento, poucos trabalhos usaram o Siops para analisar os dados de atenção básica, mas este artigo permite a viabilização de estudos, uma vez que demonstra a confiabilidade das informaçóes. Contudo, não foi analisada a consistência no tocante ao montante dos valores declarados, o que constitui uma das limitaçóes deste estudo. Uma agenda futura seria compreender as barreiras que dificultam a alimentação dos dados de maneira detalhada para os itens que compóe a atenção básica e outras subfunçóes e verificar se a melhora observada para a atenção básica e a piora para a ESF persistiram nos anos mais recentes. Bancos de dados administrativos são cada vez mais usados na saúde, principalmente para avaliaçóes econômicas. A tendência é que com todos os órgãos de auditoria e aprimoramento dos instrumentos de apuração dos dados as informaçóes sejam alimentadas com maior precisão e qualidade e que no futuro sirvam para ampliar as possibilidades de pesquisa.

\section{REFERÊNCIAS}

BEZERRA, A. F. B. et al. Avaliação da regularidade na alimentação do Sistema de Informaçóes sobre Orçamentos Públicos em Saúde (Siops) em municípios de Pernambuco, de 2000 a 2006. Cadernos de Saúde Pública, Rio de Janeiro, v. 18, n. 1, 2010.

BRASIL. Portaria no 2.023 de 23 de setembro de 2004. Define que os municípios e o Distrito Federal sejam responsáveis pela gestão do sistema municipal de saúde na organização e na execução das ações de atenção básica, e dá outras providências. Diário Oficial da Uniáo, Brasília, 24 set. 2004.

. Lei Complementar no 141, de 13 de janeiro de 2012. Regulamenta o $\$ 3$ o do art. 198 da Constituição Federal para dispor sobre os valores mínimos a serem aplicados anualmente pela Uniáo, estados, Distrito Federal e municípios em açóes e serviços públicos de saúde; estabelece os critérios de rateio dos recursos de transferências para a saúde e as normas de fiscalização, avaliação e controle das despesas com saúde nas três esferas de governo; revoga dispositivos das Leis nos 8.080, de 19 de setembro de 1990, e 8.689, de 27 de julho de 1993; e dá outras providências. Diário Oficial da Uniáo, Brasília, 16 jan. 2012a.

. Decreto no 7.827, de 16 de outubro de 2012. Regulamenta os procedimentos de condicionamento e restabelecimento das transferências de recursos provenientes das receitas de que tratam o inciso II do caput do art. 158, as alíneas "a" e "b" do inciso I e o inciso II do caput do art. 159 da Constituição, dispóe sobre os procedimentos de suspensão e restabelecimento das transferências voluntárias da União, nos casos de descumprimento da aplicação dos recursos em ações e serviços públicos de saúde de que trata a Lei Complementar no 141, de 13 de janeiro de 2012, e dá outras providências. Diário Oficial da União, Brasília, 17 out. 2012 b. 
. Ministério da Saúde. Sistema de Informações sobre Orçamentos Públicos em Saúde. Manual Siops aplicado a municípios 2014/6o bimestre. Brasília: MS; Siops, 2017a. Disponível em: <https://bit.ly/2JCqo3J>. Acesso em: 19 maio 2017.

. Ministério da Saúde. Sistema de Informaçōes sobre Orçamentos Públicos em Saúde. Orientaçóes sobre críticas e avisos gerados pelos programas Siops. Brasília: MS; Siops, 2017b. Disponível em: <https://bit.ly/3lIS3NF>. Acesso em: 19 maio 2017.

. Ministério da Saúde. Sistema de Informaçóes sobre Orçamentos Públicos em Saúde. Dúvidas frequentes. Brasília: MS; Siops, 2017c. Disponível em: <https://bit.ly/3mIDMSo>. Acesso em: 24 maio 2017.

Ministério da Fazenda. Secretaria do Tesouro Nacional. Manual de contabilidade aplicada ao setor público. 6. ed. Brasília: MF; SNT, 2017d. Disponível em: <https://bit.ly/2VEFGHO>. Acesso em: 25 nov. 2017d.

. Ministério da Saúde. Secretaria de Atenção à Saúde. Departamento de Atenção Básica. Coberturas do Saúde da Família. Brasília: MS, 2018. Disponível em: <https://bit.ly/2VAYqIf >. Acesso em: 29 out. 2018.

CAMPELLI, M. G. R.; CALVO, M. C. M. O cumprimento da Emenda Constitucional no 29 no Brasil. Cadernos de Saúde Pública, Rio de Janeiro, v. 23, n. 7, p. 1613-1623, 2007.

CAVALCANTE, D. S.; PETER, M. G. A.; MACHADO, M.V. V. Organização dos orgáos de controle interno municipal no estado do Ceará: um estudo na Regiáo Metropolitana de Fortaleza. ASAA-Advances in Scientific and Applied Accounting, v. 4, n. 1, p. 24-43, 2011.

GAMA, J. R. Transparência pública e governo eletrônico: análise dos portais dos municípios do Pará. Dissertação (Mestrado) - Núcleo de Altos Estudos Amazônicos, Universidade Federal do Pará, Belém, 2015.

GOMES, J. C. Avaliaçáo da transparência fiscal dos municípios brasileiros pelo Índice de Qualidade da Informação da Execução Orçamentária Municipal: 2003 a 2015. 2018. Dissertação (Mestrado) - Centro de Ciências Jurídicas e Econômicas, Universidade Federal do Espírito Santo, Vitória, 2018.

GONÇALVES, R. F. et al. Confiabilidade dos dados relativos ao cumprimento da Emenda Constitucional no 29 declarados ao Sistema de Informaçôes sobre Orçamentos Públicos em Saúde pelos municípios de Pernambuco, Brasil. Cadernos de Saúde Pública, Rio de Janeiro, v. 25, n. 12, p. 2612-2620, 2009.

HENRIQUE, I. C. O Siops como ferramenta de apoio à gestáo: o conhecimento dos gestores municipais de Pernambuco. In: ENCONTRO DA ABRES, 11., 2014, São Paulo, São Paulo. Anais... São Paulo: Siops, 2014. 
LIMA, C. R. A.; CARVALHO, M. S.; SCHRAMM, J. M. A. Financiamento público em saúde e confiabilidade dos bancos de dados nacionais: um estudo dos anos de 2001 e 2002. Cadernos de Saúde Pública, Rio de Janeiro, p. 1855-1864, 2006.

MEDEIROS, K. R. et al. Bases de dados orçamentários e qualidade da informação: uma avaliação do Finanças do Brasil (Finbra) e do Sistema de Informaçóes sobre Orçamentos Públicos em Saúde (Siops). Revista de Administraçáo Pública, Rio de Janeiro, v. 48, n. 5, p. 1113-1134, 2014.

PIOLA, S. F. et al. Financiamento do Sistema Único de Saúde: trajetória recente e cenários para o futuro. Análise Econômica, Porto Alegre, v. 30, 2012.

Financiamento público da saúde: uma história à procura de rumo. Rio de Janeiro: Ipea, 2013. (Texto para Discussão, n. 1846).

PIOLA, S. F.; FRANÇA, J. R. M.; NUNES, A. Os efeitos da Emenda Constitucional no 29 na alocação regional dos gastos públicos no Sistema Único de Saúde no Brasil. Revista Ciência \& Saúde Coletiva, Rio de Janeiro, v. 21, n. 2, 2016.

PRADO, C.; RITZEL, J. Apuração dos gastos próprios municipais em atenção básica: uma metodologia desenvolvida a partir do Siops. In: ENCONTRO DA ABRES, 11., 2014, São Paulo, São Paulo. Anais... São Paulo: Siops, 2014.

QUEIROZ, D. B. et al. Transparência dos municípios do Rio Grande do Norte: avaliação da relação entre o nível de disclosure, tamanho e características socioeconômicas. Revista Evidenciação Contábil \& Finanças, v. 1, n. 2, p. 38-51, 2013.

RIBEIRO, J. A.; PIOLA, S. F.; SERVO, L. M. As novas configurações de antigos problemas: financiamento e gasto com açóes e serviços públicos de saúde no Brasil. Divulgaçáo em Saúde para Debate, Rio de Janeiro, v. 37, p. 21-43, 2007.

RODRIGUES, S. V. M.; BARTOLUZZIO, A. I. S. S.; MIRANDA, L. C. O efeito da implantação do Sistema de Controle Interno Municipal na qualidade da informação prestada pelas prefeituras brasileiras: um estudo a partir dos relatórios de auditoria dos Tribunais de Contas. In: CONGRESSO UFPE DE CIÊNCIAS CONTÁBEIS, 12., 2018, Recife, Pernambuco, 2018. Anais... Recife: UFPE, 2018.

SANTOS, C. M. V. et al. Características dos municípios fluminenses e suas falhas ressalvadas nos pareceres de prestação de contas do TCE-RJ. Pensar Contábil, v. 18, n. $67,2017$.

SERVO, L. M. S.; PAIVA, A. B. Gasto com atençáo básica das três esferas de governo: possibilidades e limitaçóes das análises a partir de bases de dados orçamentário-financeiras. Brasília: Ipea, 2013.

SILVA, K. S. B. et al. Conhecimento e uso do Sistema de Informações sobre Orçamentos Públicos em Saúde (Siops) pelos gestores municipais, Pernambuco, Brasil. Cadernos de Saúde Pública, Rio de Janeiro, v. 26, n. 2, p. 373-382, 2010. 
SOUSA, I. M. C. et al. Avaliação do Siops e cumprimento da EC no 29/2000 em Pernambuco. In: ENCONTRO DA ABRES, 8., 2007, São Paulo, São Paulo. Anais... São Paulo: Siops, 2007.

TEIXEIRA, H. V.; TEIXEIRA, M. G. Financiamento da saúde pública no Brasil: a experiência do Siops. Ciência \& Saúde Coletiva, Rio de Janeiro, v. 8, n. 2, p. 379-391, 2003.

VASCONCELOS, M. T. C. et al. Funcionalidade do controle interno nos municípios: um estudo nas prefeituras de uma região metropolitana do nordeste brasileiro. Advances in Scientific and Applied Accounting, v. 5, n. 2, p. 201-221, 2012.

VIEIRA, F. S.; BENEVIDES, R. P. S. Os impactos do novo regime fiscal para o financiamento do Sistema Único de Saúde e para a efetivaçáo do direito à saúde no Brasil. Brasília: Ipea, 2016.

\section{BIBLIOGRAFIA COMPLEMENTAR}

BRASIL. Constituição da República Federativa do Brasil de 1988. Brasília: Congresso Nacional, 5 out. 1988.

. Portaria Conjunta MS/PGR no 1.163 de 11 de outubro de 2000. Estabelece diretrizes para a implementação do Siops no âmbito do Ministério da Saúde, incluindo a criação da Câmara Técnica e dos Núcleos Estaduais de Apoio ao Siops. Diário Oficial da Uniáo, Brasília, 20 out. 2000.

. Ministério da Saúde. Fundo Nacional de Saúde. Gestáo Financeira do Sistema Único de Saúde: manual básico. Brasília: MS, 2003.

. Portaria no 399 de 22 de fevereiro de 2006. Divulga o Pacto pela Saúde 2006 - Consolidação do SUS e aprova as Diretrizes Operacionais do Referido Pacto. Diário Oficial da União, Brasília, 23 fev. 2006.

DATASUS - DEPARTAMENTO DE INFORMÁTICA DO SISTEMA ÚNICO DE SAÚDE. Cadastros nacionais: municípios. Brasília: MS, 2020. Disponível em: <https://bit.ly/3lIjfw3>. Acesso em: 21 maio 2017.

IBGE - INSTITUTO BRASILEIRO DE GEOGRAFIA E ESTATÍSTICA. Indicadores sociais municipais: uma análise dos resultados do universo do Censo Demográfico 2010. Rio de Janeiro: IBGE, 2011.

MENDES, E. V. Os grandes dilemas do SUS. Salvador: Casa da Qualidade Editora, 2001. Coleção saúde coletiva. t. 2.

Data da submissão: 31/12/2017

Primeira decisão editorial em: 6/6/2018

Última versão recebida em: 14/5/2019

Aprovação final em: 27/5/2019 